\title{
Optimal cost-efficiency solution of acoustic treatment for a complex meeting room
}

\author{
Catalin BAILESCU ${ }^{1}$, Vlad IORDACHE ${ }^{1}$, and Tiberiu CATALINA ${ }^{1, *}$ \\ ${ }^{1}$ Technical University of Civil Engineering, Faculty of Building Services, Bucharest, ROMANIA
}

\begin{abstract}
Achieving high acoustic quality in meeting rooms is important for intelligibility therefore several measures are needed especially in reflective high volume rooms. This article tackles the method and the solution to renovate a complex enclosure. The study is divided in multiple stages: development of the $3 \mathrm{D}$ room model exported in ODEON acoustic software, validation of the actual condition of the room with measurements, proposing and analysing different acoustic ceiling tiles and finally selecting the optimum solution based on the cost and efficacy in reducing the reverberation time (RT). The measured RT was four times higher $(3.45 \mathrm{sec}$ at $\mathrm{f}=1 \mathrm{kHz})$ than the recommended value $(0.9 \mathrm{sec}$ at $\mathrm{f}=1 \mathrm{kHz})$. The numerical simulation results were in accordance with the experimental measurements with errors of less than $0.2 \mathrm{sec}$. Using the difference between the RT obtained with the acoustic measures and the optimum RT we were able to calculate an efficiency that was later on compared with the cost of the solution. As a conclusion, due to a large diversity of acoustic ceiling types with different prices and sound absorption coefficients it is important, especially for complex room geometries, to run simulations and to perform a cost-efficiency analysis.
\end{abstract}

\section{Introduction}

The assessment of acoustic quality of a room can be a difficult issue if one takes into account the complex structure of the sound field, especially for closed complex shapes. Hearing appreciation of the occupants may differ therefore the need for objective acoustic parameters are required. The acoustic comfort is mainly described by two parameters: noise level and reverberation time. The reverberation or the echo of the room ,repeats, the sound (eg. human speaking) thus the intelligibility in rooms with high reverberation times (RT) is very poor. Another parameter useful to determine the intelligibility of a room, especially in conference rooms is the speech transmission index. Galburn et Kitpci [1] have studied the speech transmission index (STI) using the RT and the signal-tonoise ratio (Lsn) for different enclosed spaces. During the experimental campaign they varied the absorption of the room and the Lsn. There results demonstrated that the differences between measured and predicted STIs were on average lower than 0.06 . The reverberation time affects the STI and to lower it the main solutions are to modify/change the room materials to absorb a larger quantity of energy of the sound wave.

Achieving a good acoustic is essential for productivity and this aspect was reported in multiple articles $[2][3][4][5]$. It is clear that there is an urgent need to find a solution but the question that arise is ,What is the optimum solution and what is the best calculation method to correctly estimate the impact of each solution?".

The reverberation phenomenon may be positive in certain cases as it increases the intensity of the sound, for example in music halls or can be negative then it will extend the sound duration even to masking it. Therefore, it is important to find an optimum RT. Based on the volume and destination of the room there are recommendation on the optimum reverberation time, usually these values are to be fulfilled for the $500 \mathrm{~Hz}$ frequency. There is no recommendation on the optimum RT for each frequency [6].

Multiple solutions can be found in the literature but most of them indicate the use of acoustic ceilings. The standards and reviews mention intensively these acoustic renovation measures [7]. Gramez and Boubenider [8] have realized an analysis on the acoustic comfort for a conference room and found a poor acoustic environment due to the finishing materials employed, especially for the floors and facade. Munteanu et al. [9] have studied the acoustic proprieties of the Lecture Hall from the Faculty of Building Services in Cluj-Napoca and proposed three renovation measures that met the optimum RT in the presence of $100 \%$ occupation.

Nowoświat et al. [10] have used a method to estimate reverberation time in auditorium rooms using a statistical learning method and compared it with measurement data and numerical simulations.

\footnotetext{
* Corresponding author: tiberiu.catalina@gmail.com
} 
The purpose of this article is to find optimum solution for acoustic renovation of a meeting room where speech intelligibility is a key issue. Moreover, we will prove that numerical simulations are the right choice in the evaluation of the reverberation time and the article will answer the demanded question asked previously.

\section{Study case}

The analysed meeting room is found on the ground floor of the Faculty of Building Services and it serves mostly for student's public defence of bachelor, master and $\mathrm{PhD}$ thesis, therefore of high importance. In order to determine the geometrical characteristics and the type of materials present inside, a technical inspection was performed on the analysed test room (Figure 1).

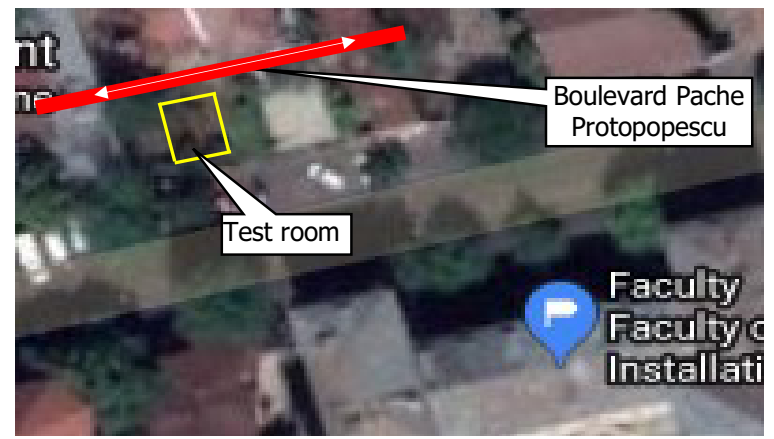

Fig. 1. Position of the test room in the building

As a result of the measurements, the following geometric characteristics of the room were found: length: $13,4 \mathrm{~m}$; Width: $7.68 \mathrm{~m}$; height: $4,01 \mathrm{~m}$ and a volume: $392.25 \mathrm{~m}^{3}$. The room has a rectangular geometric shape and the building elements are composed of different materials. The visual and technical inspection revealed the following:

- The walls are full of brick covered with plaster $\left(\mathrm{A}=191 \mathrm{~m}^{2}\right)$

- Columns are made of full brick covered with plaster $\left(\mathrm{A}=37.68 \mathrm{~m}^{2}\right)$

- The floor is made of marble $\left(\mathrm{A}=101.4 \mathrm{~m}^{2}\right)$

- Heaters are made of steel -5 pieces $\left(A=7.6 \mathrm{~m}^{2}\right)$

- The rear table, the hanger and the door are made of wood $\left(\mathrm{A}=101.4 \mathrm{~m}^{2}\right)$

- Small wooden tables -8 pieces $\left(A=22.48 \mathrm{~m}^{2}\right)$

- The seats are made of soft wood - 42 pieces $(\mathrm{A}=$ $35.07 \mathrm{~m}^{2}$ )

- The ceiling is made of plaster $\left(\mathrm{A}=101.4 \mathrm{~m}^{2}\right)$

- The windows are double wood pane -8 pieces $\left(\mathrm{A}=25.36 \mathrm{~m}^{2}\right)$

- The lamps are made of aluminium - 47 pieces $\left(\mathrm{A}=0.423 \mathrm{~m}^{2}\right)$

- The ventilation grilles are made of PVC - 7 pieces $\left(\mathrm{A}=101.4 \mathrm{~m}^{2}\right)$
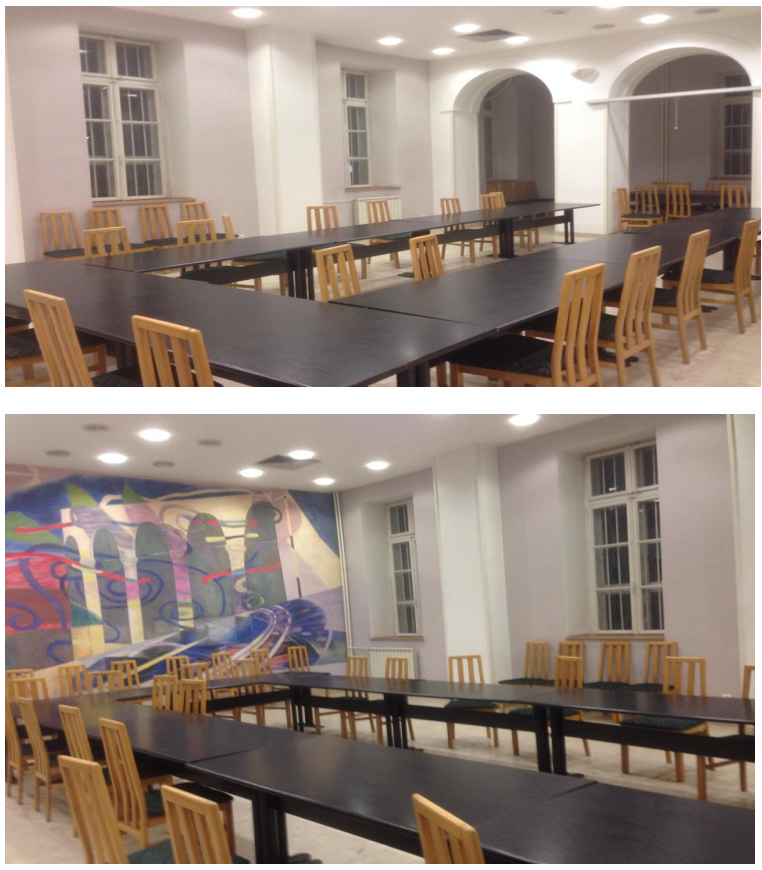

Fig. 2. Photos of the study case meeting room

All the materials and room elements have been measured for accurate calculations of the reverberation time.

\section{Numerical model}

The numerical analysis was realized using the Odeon acoustic software [11], but first it was mandatory to build the $3 \mathrm{D}$ real room. The most used program for $3 \mathrm{D}$ modelling is Google Sketchup capable of drawing simple geometric rooms to very complex ones. The next step after the creation of the architectural model was to import it into Odeon, adding noise sources, receivers, and assigning materials to each surface. The meeting room must comply with the acoustic comfort conditions imposed by the norms and it is characterized by several different operating conditions, depending on the level of furnishing and the occupancy level of the room. However, the acoustic norms [REF] do not clearly specify the operating status of the room that must meet the acoustic comfort conditions.

As a result, the room should satisfy these acoustic comfort conditions under the most unfavourable operating conditions, e.g with a minimum of furniture and occupants. If the conditions of acoustic comfort are reached in this reference/most exigent conditions in the event of a more intense operation (higher level of furniture or number of people) the acoustic comfort conditions will be respected. The first stage of the numerical study was the validation of the model, therefore we have measured experimentally the reverberation time for the frequencies $125 \mathrm{~Hz}$ to 8000 $\mathrm{Hz}$ and compared the results with the simulation data and the recommended values by the norms. It was critical for this stage to have a correct $3 \mathrm{D}$ model. The 
following images prove that we have respected almost perfectly the geometry of this complex room:
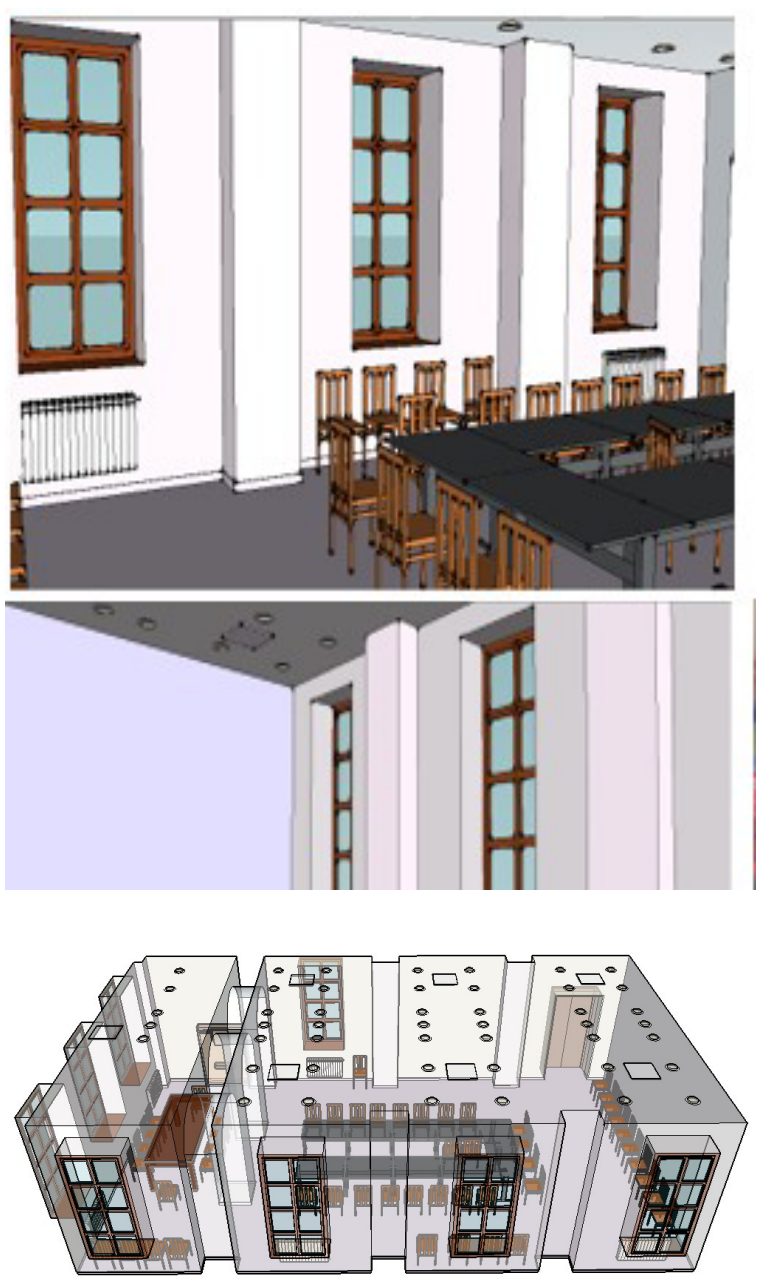

Fig. 3. Google Sketchup 3D model of the room versus real test room

The sound absorbent coefficients used during the simulations are summarized in the following table

Table 1. Sound absorption coefficients of the materials.

\begin{tabular}{|c|c|c|c|c|c|c|c|}
\hline & $\begin{array}{c}\mathbf{6 3} \\
\mathbf{H z}\end{array}$ & $\begin{array}{c}\mathbf{1 2 5} \\
\mathbf{H z}\end{array}$ & $\begin{array}{c}\mathbf{2 5 0} \\
\mathbf{H z}\end{array}$ & $\begin{array}{c}\mathbf{5 0 0} \\
\mathbf{H z}\end{array}$ & $\begin{array}{c}\mathbf{1 K} \\
\mathbf{H z}\end{array}$ & $\begin{array}{c}\mathbf{2 K} \\
\mathbf{H z}\end{array}$ & $\begin{array}{c}\mathbf{4 K} \\
\mathbf{H z}\end{array}$ \\
\hline Walls & 0,02 & 0,02 & 0,03 & 0,03 & 0,04 & 0,05 & 0,07 \\
\hline Floor & 0,01 & 0,01 & 0,01 & 0,01 & 0,01 & 0,02 & 0,02 \\
\hline $\begin{array}{c}\text { Heating } \\
\text { elements }\end{array}$ & 0,01 & 0,01 & 0,01 & 0,01 & 0,01 & 0,01 & 0,02 \\
\hline $\begin{array}{c}\text { Wood } \\
\text { tables }\end{array}$ & 0,19 & 0,19 & 0,14 & 0,09 & 0,06 & 0,06 & 0,05 \\
\hline Windows & 0,35 & 0,35 & 0,25 & 0,18 & 0,12 & 0,07 & 0,04 \\
\hline Ceiling & 0,14 & 0,14 & 0,1 & 0,06 & 0,05 & 0,04 & 0,03 \\
\hline $\begin{array}{c}\text { Vent } \\
\text { diffusers }\end{array}$ & 0,1 & 0,16 & 0,2 & 0,3 & 0,35 & 0,29 & 0,26 \\
\hline
\end{tabular}

\subsection{Validation of the numerical model}

It is noticed that the reverberation time of the model obtained using the numerical simulation with Odeon software are almost equal to the ones determined experimentally with differences of less than 0.2 seconds. It results that we have a good calibration of the virtual model made in Odeon, so this model can be further used for acoustic treatment of this room. Compared with the optimal RT60 proposed by the norms for this type of room and volume the measured/calculated reverberation time is exceeded by 4 times and it needs immediate treatment to enhance intelligibility and to ensure acoustic comfort in the room.

Table 2. Validation of the reference case simulation with the experimental data - RT60 values.

\begin{tabular}{|l|c|c|c|c|c|c|c|}
\hline & $\mathbf{6 3}$ & $\mathbf{1 2 5}$ & $\mathbf{2 5 0}$ & $\mathbf{5 0 0}$ & $\mathbf{1 K}$ & $\mathbf{2 K}$ & $\mathbf{4 K}$ \\
& $\mathbf{H z}$ & $\mathbf{H z}$ & $\mathbf{H z}$ & $\mathbf{H z}$ & $\mathbf{H z}$ & $\mathbf{H z}$ & $\mathbf{H z}$ \\
\hline Experiment & 2,33 & 3,80 & 4,40 & 4,31 & 3,45 & 2,72 & 2,33 \\
\hline Simulation & 2,50 & 3,72 & 4,43 & 4,34 & 3,55 & 2,85 & 2,50 \\
\hline Norm & 0,95 & 0,95 & 0,95 & 0,95 & 0,95 & 0,95 & 0,95 \\
\hline
\end{tabular}

The experimental measurements were realized with high precision class 1 sound meter Bruel and Kjaer model 2250 during night time in order to avoid any sound pressure disturbance. As long as the validation was proven the next step was a detailed analysis using simulations.

\subsection{Results on the reference case}

The acoustic maps of the room noise level (SPL), the speech transmission index (STI), and the reverberation time (RT60) for the $1000 \mathrm{~Hz}$ frequency will be presented below. The acoustic maps were made with the following characteristics: the receptor height is $1.5 \mathrm{~m}$ from the floor and the distance between each receiver is $0.3 \mathrm{~m}$. There were a total of 338 receivers for each acoustic map. The acoustic map of the room noise level was made for a midrange $80 \mathrm{dBA}$ noise source characteristic of a normal speaker.

Figure 4 shows that in the middle of the room the noise level is $80 \mathrm{dBA}$ (red) and behind the columns is $78 \mathrm{dBA}$ (blue). This decrease is due to the sound spreading effect of sound energy collisions.

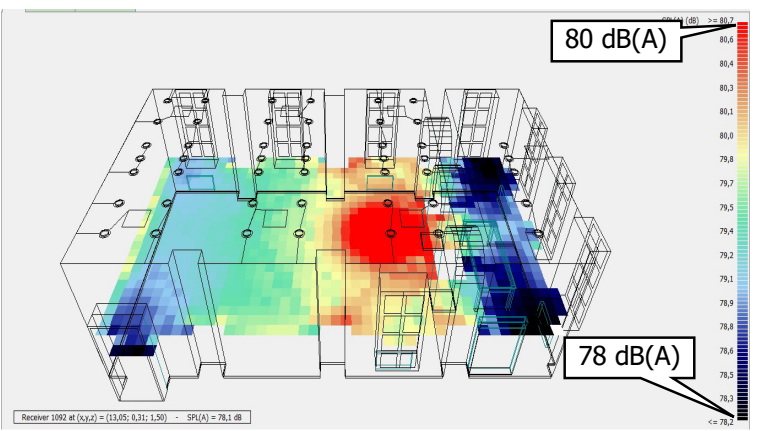

Fig. 4. Sound pressure level (SPL) acoustic map of the room

The acoustic map of the speech transmission index (Figure 5) in the room was made for the same $80 \mathrm{dBA}$ noise source. It can be seen that the speech transmission index has values between $0.3-0.45$, which results in a 
poor quality of speech intelligibility due to the reflective materials used.

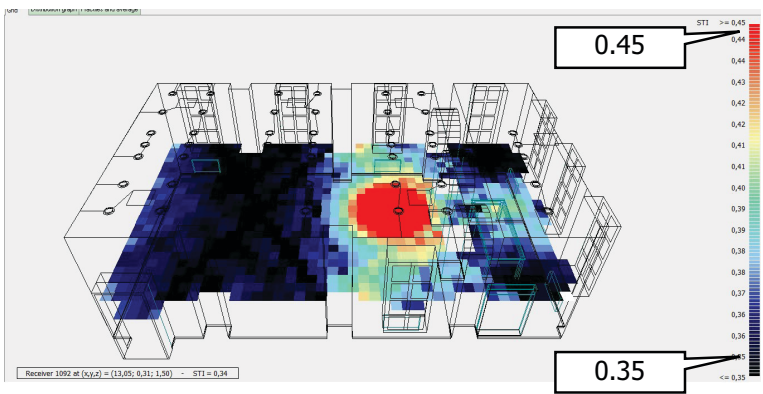

Fig. 5. Speech transmission index (STI) acoustic map of the room

Figure 6 shows the acoustic map of the reverberation time for the $1000 \mathrm{~Hz}$ frequency. The reverberation time in the room for the $1000 \mathrm{~Hz}$ frequency is approximately 4.40 seconds. It is found that the reverberation distribution is uniform in the room, only near the source it decreases to the minimum value of $2.05 \mathrm{~s}$.

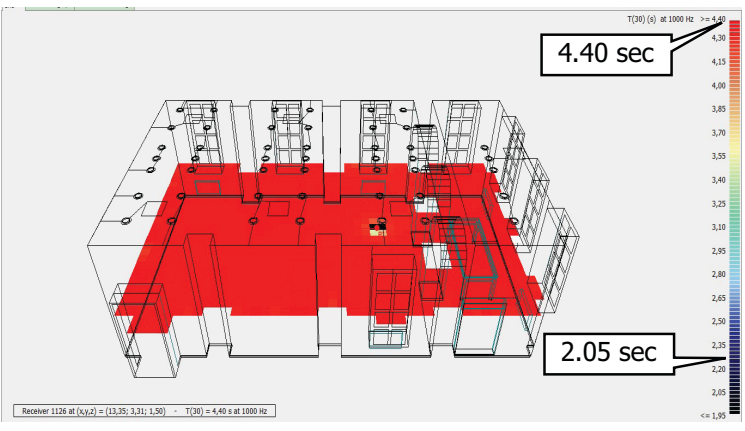

Fig. 6. Reverberation time (RT60) acoustic map of the room

The conclusions of both the experimental campaign and the numerical simulations are the same: the room has a poor speech transmission index and the reverberation is excessive.

\section{Optimal acoustic solution}

Finding the best cost/efficiency solution may be a challenge especially for such high reverberation times and complex geometry. This involves consulting manufacturers' tables, specifying the absorption coefficients under laboratory conditions, as well as different combinations of these materials. Field conditions are different from lab conditions, more corrections and adjustments to ideal situations are required and sound leakage through secondary paths has to be added to the equation, so it has been decided to use numerical simulations.

In addition to the technical criteria, other considerations, such as financial conditions, commercial availability of materials or even aesthetic criteria, must be taken into account. Because the absorption coefficient of the ceiling is very low, it is proposed to add additional layers to substantially modify the $\alpha$-ceiling.
As a result, the first acoustic treatment solution involves covering the ceiling with a new absorbing surface represented by acoustic tiles. The acoustic treatment of the meeting room will be achieved through the analysis of 10 solutions represented by installing different type of acoustic ceiling tiles. The main producers of sound absorbing ceiling tiles are from KNAUF and ARMSTRONG thus it was decided to compare multiple types from these fabricants.

Table 3. Acoustic ceiling solutions.

\begin{tabular}{|c|c|}
\hline $\begin{array}{c}\text { Solution } \\
\text { no. }\end{array}$ & Acoustic tiles models \\
\hline S1 & Thermatex Star KNAUF \\
\hline S2 & Thermatex Antaris C KNAUF \\
\hline S3 & Thermatex Acoustic KNAUF \\
\hline S4 & Thermatex SIlece KNAUF \\
\hline S5 & Thermatex Alpha HD KNAUF \\
\hline S6 & Scalacoustic ARMSTRONG \\
\hline S7 & Optima ARMSTRONG \\
\hline S8 & Perla ARMSTRONG \\
\hline S9 & Sierra ARMSTRONG \\
\hline S10 & Ultima ARMSTRONG \\
\hline
\end{tabular}

In total there were made 10 simulations and for each of these the ceiling sound absorption coefficient was modified according to the fabricant technical datasheet. For example, the Thermatex Star KNAUF has the following values:

Table 4. Sound absorption coefficients for the 10 solutions

\begin{tabular}{|c|r|r|r|r|r|r|}
\hline Solution & $\begin{array}{c}\mathbf{1 2 5} \\
\mathbf{H z}\end{array}$ & $\begin{array}{c}\mathbf{2 5 0} \\
\mathbf{H z}\end{array}$ & $\begin{array}{c}\mathbf{5 0 0} \\
\mathbf{H z}\end{array}$ & $\begin{array}{r}\mathbf{1 K} \\
\mathbf{H z}\end{array}$ & $\begin{array}{r}\mathbf{2 K} \\
\mathbf{H z}\end{array}$ & $\begin{array}{c}\mathbf{4 K} \\
\mathbf{H z}\end{array}$ \\
\hline S1 & 0,50 & 0,40 & 0,55 & 0,70 & 0,65 & 0,45 \\
\hline S2 & 0,40 & 0,60 & 0,60 & 0,85 & 0,85 & 1,00 \\
\hline S3 & 0,35 & 0,40 & 0,65 & 0,85 & 0,95 & 0,95 \\
\hline S4 & 0,40 & 0,55 & 0,85 & 1,00 & 1,00 & 1,00 \\
\hline S5 & 0,45 & 0,70 & 0,80 & 0,90 & 1,00 & 1,00 \\
\hline S6 & 0,35 & 0,35 & 0,55 & 0,75 & 0,65 & 0,60 \\
\hline S7 & 0,35 & 0,75 & 1,00 & 0,80 & 0,90 & 0,95 \\
\hline S8 & 0,50 & 0,85 & 0,95 & 0,95 & 0,95 & 1,00 \\
\hline S9 & 0,45 & 0,75 & 0,85 & 0,85 & 1,00 & 1,00 \\
\hline S10 & 0,40 & 0,80 & 1,00 & 0,95 & 1,00 & 1,00 \\
\hline
\end{tabular}

Using the simulation analysis, it was obtained the RT for all frequencies. As it can be seen from Figure 7 the results are enhanced as the reverberation time is very close to the recommended values by the norms but still only at $\mathrm{f}=8000 \mathrm{~Hz}$ fully respects the limit.

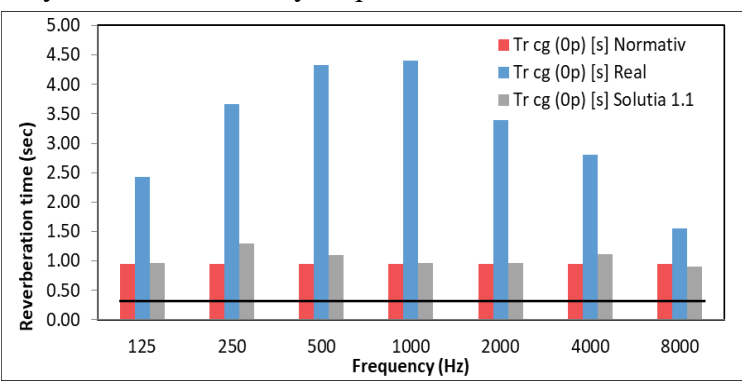

Fig. 7. Comparison of reverberation time for solution S1.1 with the norm and the real actual case

The analysis was realized for all the proposed solutions (see Table 5) but only for S 1.8 the RT was the most efficient. 
Table 5. Reverberation time simulation results

\begin{tabular}{|c|c|c|c|c|c|c|c|}
\hline & $\begin{array}{r}\mathbf{1 2 5} \\
\mathbf{H z}\end{array}$ & $\begin{array}{c}\mathbf{2 5 0} \\
\mathbf{H z}\end{array}$ & $\begin{array}{c}\mathbf{5 0 0} \\
\mathbf{H z}\end{array}$ & $\begin{array}{r}\mathbf{1 K} \\
\mathbf{H z}\end{array}$ & $\begin{array}{r}\mathbf{2 K} \\
\mathbf{H z}\end{array}$ & $\begin{array}{c}\mathbf{4 K} \\
\mathbf{H z}\end{array}$ & $\begin{array}{c}\mathbf{8 K} \\
\mathbf{H z}\end{array}$ \\
\hline Real & 2,43 & 3,67 & 4,33 & 4,40 & 3,39 & 2,81 & 1,55 \\
\hline Norm & 0,95 & 0,95 & 0,95 & 0,95 & 0,95 & 0,95 & 0,95 \\
\hline S1 & 0,97 & 1,30 & 1,10 & 0,96 & 0,97 & 1,11 & 0,90 \\
\hline S2 & 1,15 & 0,99 & 1,05 & 1,04 & 0,82 & 0,65 & 0,68 \\
\hline S3 & 1,26 & 1,33 & 0,82 & 0,85 & 0,75 & 0,71 & 0,71 \\
\hline S4 & 1,15 & 1,06 & 0,82 & 0,85 & 0,68 & 0,65 & 0,59 \\
\hline S5 & 1,15 & 0,89 & 0,85 & 0,81 & 0,68 & 0,65 & 0,59 \\
\hline S6 & 1,26 & 1,47 & 1,12 & 0,93 & 0,99 & 0,97 & 0,79 \\
\hline S7 & 1,25 & 0,85 & 0,71 & 0,87 & 0,78 & 0,69 & 0,58 \\
\hline S8 & 0,99 & 0,79 & 0,75 & 0,77 & 0,68 & 0,65 & 0,59 \\
\hline S9 & 1,07 & 0,85 & 0,82 & 0,85 & 0,68 & 0,65 & 0,59 \\
\hline S10 & 1,15 & 0,82 & 0,72 & 0,77 & 0,68 & 0,65 & 0,59 \\
\hline
\end{tabular}

In choosing an optimal solution, not only analysing reverberation times is important but also the total cost of implementation consequently a formula was used:

$\mathrm{ERR}=\mathrm{RT}_{\text {solution }}-\mathrm{RT}_{\text {norm }}$, if $\mathrm{RT}_{\text {solution }}>\mathrm{RT}_{\text {norm }}$

$\mathrm{ERR}=0$, if $\mathrm{RT}_{\text {solution }}<\mathrm{RT}_{\text {norm }}$

$\mathrm{SSE}=\sum \mathrm{ERR}^{2}$

The optimal reverberation time can be a difficult challenge to achieve especially for lower frequencies. The costs from Table 6 do not include the installation of the acoustic tiles or other structural or fixation system, however it is expected that these costs to be the same for all 10 solutions.

Table 6. Comparison relative error/price

\begin{tabular}{|c|c|c|c|c|c|c|c|c|}
\hline Sol. & $\begin{array}{c}\mathbf{1 2 5} \\
\mathbf{H z}\end{array}$ & $\begin{array}{c}\mathbf{2 5 0} \\
\mathbf{H z}\end{array}$ & $\begin{array}{c}\mathbf{5 0 0} \\
\mathbf{H z}\end{array}$ & $\begin{array}{c}\mathbf{1 K} \\
\mathbf{H z}\end{array}$ & $\begin{array}{c}\mathbf{2 K} \\
\mathbf{H z}\end{array}$ & $\begin{array}{c}\mathbf{4 K} \\
\mathbf{H z}\end{array}$ & $\begin{array}{c}\mathbf{S S E} \\
\mathbf{s e c}^{\mathbf{2}}\end{array}$ & $\begin{array}{c}\mathbf{C o s t} \\
\boldsymbol{\epsilon}\end{array}$ \\
\hline S1 & 0.00 & 0.12 & 0.02 & 0.00 & 0.00 & 0.03 & 0.172 & 787 \\
\hline S2 & 0.04 & 0.00 & 0.01 & 0.01 & 0.00 & 0.00 & 0.060 & 703 \\
\hline S3 & 0.10 & 0.14 & 0.02 & 0.01 & 0.04 & 0.06 & 0.423 & 1617 \\
\hline S4 & 0.04 & 0.01 & 0.00 & 0.00 & 0.00 & 0.00 & 0.052 & 4294 \\
\hline S5 & 0.04 & 0.00 & 0.00 & 0.00 & 0.00 & 0.00 & 0.040 & 2143 \\
\hline S6 & 0.10 & 0.27 & 0.03 & 0.00 & 0.00 & 0.00 & 0.397 & 399 \\
\hline S7 & 0.09 & 0.00 & 0.00 & 0.00 & 0.00 & 0.00 & 0.090 & 1335 \\
\hline S8 & 0.00 & 0.00 & 0.00 & 0.00 & 0.00 & 0.00 & 0.002 & 1601 \\
\hline S9 & 0.01 & 0.00 & 0.00 & 0.00 & 0.00 & 0.00 & 0.014 & 1818 \\
\hline S10 & 0.04 & 0.00 & 0.00 & 0.00 & 0.00 & 0.00 & 0.040 & 2142 \\
\hline
\end{tabular}

From Figure 7 it can be concluded that the best measure is the model Thermatex Antaris C KNAUF as it performance is good and has the lowest price (aprox. $\left.7 € / \mathrm{m}^{2}\right)$.

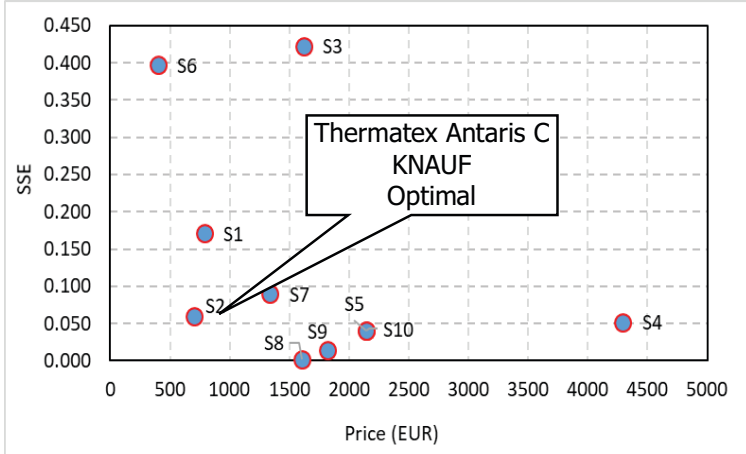

Fig. 7. SSE versus solution price

\section{Conclusions}

Acoustic comfort is a part of the indoor environmental quality and of high importance especially in meeting of conference rooms. To determine correctly the echo of a room the use of numerical simulations is the right way particularly for complex geometries where the simple use of Sabine formula will introduce large errors and therefore the acoustic renovation solution will be false. It was proven with this article that complex geometries can be simulated from an accurate $3 \mathrm{D}$ model and the data were validated with experimental measurements conducted with a class 1 precision sound meter. The study case reverberation times were found to be very high ( $>3$ seconds) therefore a parametric study with different acoustic ceiling solutions was initiated. The RT values were determined for each solution and an optimal cost-efficiency measure was selected.

\section{References}

1. L. Galburn, K.Kitapci, Accuracy of speech transmission index predictions based on the reverberation time and signal-to-noise ratio, Applied Acoustics, Vol. 81 (2014)

2. M. Pierrette, E. Parizet, P. Chevret, J. Chatillon, Noise effect on comfort in open-space offices: development of an assessment questionnaire, Ergonomics, 58 (2015)

3. Y. AlHorr, M. Arif, A. Kaushik, A. Mazroei, M. Kat afygiotou, E.ElsarragOccupant productivity and office indoor environment quality: a review of the literature, Build Environ, 105 (2016)

4. W. Yang, J.S. BradleyEffects of room acoustics on the intelligibility of speech in classroom for young children, J Acoust Soc Am, 125 (2009)

5. M. Klatte, T. Lachmann, M. MeisEffects of noise and reverberation on speech perception and listening comprehension of children and adults in a classroom-like setting, Noise Health, 12 (2010)

6. STAS 9783/0-83, Parameters for the acoustic design and control of public audition rooms.

7. NSI/ASA S12.60. Acoustical performance criteria, design requirements, and guidelines for schools, Part 1: Permanent schools. New York: American National Standards Institute, Inc. [ANSI] and Acoustical Society of America [ASA]; 2010.

8. A. Gramez, F. Boubenider, Acoustic comfort evaluation for a conference room: A case study, Applied Acoustics, 118 (2017)

9. C. Munteanu, D. Bogdan, M. Ligia Mihaela, N. Cobîrzan, D. R.Tămaș-Gavrea, F. Babota, The acoustic properties of the lecture hall of the Faculty of Building Services in Cluj-Napoca, Procedia Manufacturing, 22 (2018)

10. A. Nowoświat, M. Olechowska, J. Ślusarek, Prediction of reverberation time using the residual minimization method, Applied Acoustics, 106 (2016)

11. ODEON Acoustic Software for Room Analysis https://odeon.dk/acoustics_simulation_software/ 